\section{Gender and alcohol consumption and alcohol-related problems in Latin America and the Caribbean ${ }^{1}$}

Key words: alcohol drinking, gender and health, culture, Latin America, Caribbean.

\footnotetext{
Based on: Pyne HH, Claeson M, Correia M. Gender dimensions of alcohol consumption and alcohol-related problems in Latin America and the Caribbean. Washington, D.C.: International Bank for Reconstruction and Development/The World Bank; 2002. (World Bank Discussion Paper No. 433).
}

Over the last decade alcohol consumption has become an increasing concern as a public health issue. Alcohol is one of the major causes of global disease, with men bearing most of the burden of alcoholrelated diseases. In developing nations, alcohol ranks as the fourth cause of disability among men. Alcohol consumption is particularly problematic in Latin America and the Caribbean (LAC). While the proportion of all deaths worldwide that can be attributed to alcohol use is $1.5 \%$, that figure is $4.5 \%$ for the LAC nations.

Efforts to reduce the negative social and public health effects of alcohol need to take into account the sociocultural context in which drinking occurs, and especially gender roles. That is according to a discussion paper recently released by the World Bank that is entitled Gender Dimensions of Alcohol Consumption and Alcohol-Related Problems in Latin America and the Caribbean.

The World Bank document affirms that alcohol use and abuse are linked to men's and women's roles and expectations in society. Men are more likely to drink heavily and excessively than are women, and men are also less likely to abstain from alcohol consumption. Furthermore, men and women are subjected to different expectations and meanings in their use of alcohol as well as in the way they respond to it.

Adverse effects of alcohol consumption range from acute maladies and injuries to a host of longterm chronic conditions that include brain damage, high blood pressure, stroke, cancers, and muscle and bone diseases.

The individual who consumes the alcohol is not the only one affected by it; the drinker's family and community also bear its costs. In addition, alcohol plays an important role in instigating unsafe sexual practices and violent behaviors, particularly within the family. A primary example is domestic violence, much of which is directed against women and children.

\section{GENDER DIMENSIONS OF ALCOHOL USE}

Within the LAC area, there are large variations in the levels of alcohol consumption and the preferred types of alcoholic beverage, such as beer, wine, or spirits. For example, Mexico has been characterized as a "dry culture," where daily consumption is not a common practice. Instead, alcohol use 
is marked by infrequent, heavy binge drinking such as during festivals. In Brazil, on the other hand, drinking begins early in life, commonly involves the family, and is integrated into daily life. Despite that general pattern, occasions of excessive drinking in Brazil are also common, such as during Carnival, soccer games, and holiday celebrations.

Epidemiological studies of LAC countries have shown that men are more likely to drink heavily and excessively than are women, and that women are more likely to abstain than are men. In Mexico, for example, a national addiction survey found that $27 \%$ of men and $63 \%$ of women had drunk no alcohol in the preceding year. About $14 \%$ of the Mexican men were considered heavy drinkers, but that was true for just $1 \%$ of the women. A survey in Argentina found that among women in Buenos Aires only 1\% drank heavily, in comparison to $12 \%$ of men.

Binge drinking is another area of alcohol use where men and women differ. Although both women and men in LAC countries engage in drinking during festivals, binge drinking is more common among men. In addition, men are provided with more social occasions that promote drinking, such as sporting events, than are women. In general, intoxication is more socially acceptable for men than it is for women. In Honduras, for example, focus group discussions with men indicated that women are expected to tolerate their male partners' intoxication.

There are also differences in drinking patterns according to geography. A national survey of alcohol consumption in Costa Rica in 1981 showed that, depending on the region of the country, the proportion of abstainers among women ranged from $34 \%$ to $61 \%$; the range for men was from $12 \%$ to $22 \%$.

Gender also interacts with other variables such as age, socioeconomic status, and race in influencing drinking levels and patterns. In Argentina, for example, among men in wealthy areas, $0.6 \%$ were alcoholics and $7.5 \%$ were heavy drinkers. In poor areas, in contrast, the respective figures were $13 \%$ and $20 \%$. Another survey in Argentina found that the rate of alcoholism in slum areas was more than three times the rate in higher-income areas.

\section{LEGISLATIVE AND POLICY RESPONSES}

What actions should a government take in order to reduce alcohol consumption to a socially efficient level? The alcohol policies that a government adopts should be based on effectiveness as well as cost of implementation. One limitation to formulating economically sound alcohol policies is the shortage of information on the effectiveness of such policies in developing countries; alcohol policies and programs have mainly been evaluated in industrialized nations.

\section{Types of alcohol policies}

Alcohol policies can be classified according to four major objectives: 1) preventing drinking and high-risk drinking behaviors, 2) reducing harm to individual consumers as well as to families and communities, 3) regulating the availability of alcohol and the conditions of its use, and 4) providing treatment for individuals with drinking problems.

High-risk drinking behaviors may be prevented by prompting individuals to change their behavior through information, education, and communication (IEC) and through disincentives and punishment. Similar to many antitobacco campaigns, the IEC approach with alcohol provides potential drinkers with information on the harm posed by alcohol. The approach is intended to prevent or at least delay drinking, or to change the drinking norms. Another prevention method is to put in place disincentives or punishments for irresponsible behavior, such as by imposing penalties for drunk driving. Governments have also applied environmental interventions such as creating alternatives to alcoholic beverages and developing recreational activities for youths that do not involve drinking. These strategies focus on promoting an environment that supports abstention from or limited use of alcohol.

The second area of intervention, harm reduction, aims not to stop the drinking itself but to prevent drinking's negative consequences such as drunk driving. Examples of these interventions include the use of designated drivers and the provision of free public transportation during festivals and holidays.

The third type of alcohol policy involves regulating the availability of alcohol and its conditions of use. Regulation can range from total prohibition to imposing taxes. Availability is affected by restricting production, requiring licensing of sales outlets, restricting days and hours of sales, rationing sales, limiting drinking to specific designated settings, and limiting the number of places of sale. Other common policy actions include setting a minimum age limit for serving and buying alcohol, refusing to serve those already intoxicated, and regulating the advertising of alcoholic beverages by private companies.

The fourth area of policy intervention is providing treatment for individuals who engage in problem drinking. Such treatment may be offered by separate programs or may be integrated into existing health services and social services programs. 


\section{Alcohol legislation}

Beginning in the 1960s a few LAC countries formulated explicit national alcohol policies. The measures were driven by fiscal motives rather than by public health concerns. They concentrated on taxation of production and sales. Religious and moral arguments also propelled these policies.

Current legislative actions in the LAC countries primarily seek to limit the availability of alcoholic beverages. Alcohol control measures take diverse forms: government monopolies on production and sales, special taxes on alcohol beverages, minimum-age limits, sales restrictions set by licensing outlets, rationing of purchases, and limitations on the times of sale.

A minimum drinking age is the most common restriction on alcohol use. Almost all of the LAC countries have set 18 years of age as the minimum. Chile, where the drinking age is 21 , is the sole exception. Nevertheless, these laws are seldom enforced. For example, a study in Brazil showed that $5 \%$ of children between the ages of 9 and 11 years of age drank in bars, as did $9 \%$ of children between 15 and 17 .

The governments of Chile, Colombia, and Venezuela have restricted drinking to certain times of the day and limited the drinking to specified venues. Venezuela additionally regulates drinking on planes and boats and in sports centers. Brazil is the only LAC country that levies penalties and fines to discourage drinking in the workplace.

Bans and restrictions on advertising have also been adopted in many LAC nations. Costa Rica's National Institute on Alcoholism and Drug Dependence has been screening alcohol-related advertising since 1975. El Salvador and Paraguay have enacted legislation regulating alcohol advertising on television and in the movies; both countries also require alcoholic products to bear warning labels.

Governmentally set standards for treating alcohol dependency and rehabilitating alcoholics are limited by a lack of early detection and care. Moreover, treatment or support services are not coordinated with punitive measures such as fines and arrests. These failures limit the effectiveness of the legislation that the LAC countries have approved.

\section{RECOMMENDATIONS}

\section{Policy and program interventions}

Alcohol policies should address the multiple determinants of alcohol abuse by putting in place cost-effective, culturally appropriate, sustainable interventions; preventing alcohol abuse and dependency; and reducing alcohol-related risks to the in- dividual drinker and to other persons. The recommended public health approach includes a focus on risk behaviors and the enabling and reinforcing factors influencing those behaviors as well as a focus on the individuals or populations at risk.

Alcohol policy options for the LAC countries include levying taxes, setting product safety standards, licensing production, promoting health education, controlling advertisements, enacting drunk-driving laws and minimum-age limits, and restricting the times and conditions of beverage sales. Public education could encompass school health education programs, media campaigns, and educational approaches targeting pregnant women, commercial sex workers, and victims of physical and sexual abuse. Consumer information, such as facts about the dangers of drinking during pregnancy, is an important public health tool. However, because the informal sector supplies a significant proportion of the alcoholic beverages consumed in the LAC nations, all these measures and their tradeoffs have to be carefully evaluated, especially the measures aiming at reducing access to alcohol.

The majority of existing alcohol policies in LAC countries focus on controlling the availability of alcohol. At the very minimum, these policies need to be enforced and their effectiveness evaluated. However, the current policies neglect the stark gender dimensions of alcohol consumption and alcohol-related problems. Despite the overwhelming representation of men in alcohol-related problems, and the prevailing norms that support and encourage drinking among men, no existing interventions in LAC countries explicitly consider gender.

Gender analysis of alcohol consumption and alcohol-related problems indicates that interventions, particularly in the areas of prevention and harm reduction, ought to focus on changing sociocultural norms about gender and drinking. It is especially important to focus on the norms that promote high-risk drinking behaviors among males and to target the mechanisms that socialize both genders about drinking and drunkenness. Interventions should be specific to the sociocultural context in which drinking occurs, including gender roles and identity. In designing interventions, gender differences in alcohol consumption levels and patterns should be assessed carefully and thoroughly. Using these dimensions to understand gender differences in drinking behaviors would enhance the efficiency and effectiveness of the policy interventions.

\section{Research}

To create alcohol intervention policies, much more research in a number of areas is needed. Al- 
cohol research in the LAC area is uneven. While some countries, such as Brazil, Costa Rica, and Mexico, have produced studies that provide insight into patterns of drinking and sociocultural factors, other LAC countries have not done that kind of research. Particular attention should be paid to countries where consumption levels are high and where there is limited information on the patterns of alcohol consumption, especially its gender dimensions.

The public health literature on alcohol use remains largely entrenched in the medical "disease" model. It still lacks information on the social impacts produced by alcohol use through violence and sexual risk behaviors. The LAC countries need further studies of gender differences in the social impacts of alcohol on families and communities, including suicide, crime, and violence, among men as well as against women and children.

Alcohol's impact on household dynamics also needs more investigation. Such studies should include the impact of drinking on income and expenditures and its impact on gender roles within families.

Longitudinal studies should be considered, to provide information on trends and patterns of alcohol consumption among men and women and particularly among the young.

There are unanswered questions about gender roles. These include how alcohol use varies across age, racial, and social class lines and how males and females are socialized about drinking.

There is no inventory of current antialcohol interventions in the LAC countries. Such an inventory, listing who is doing what and evaluating the interventions that LAC governments and civil society organizations are carrying out, needs to be undertaken.

The complete report can be purchased for US\$ 10 from the World Bank, in either English or Spanish. Information on buying the report in English is available on the Internet at http://publications.worldbank.org/ecommerce/catalog/product?item_id=1110038; the Web page for information on the Spanish-language report is: http://publications.worldbank.org/ecommerce/catalog/product?item_id=1312633.

\section{SINOPSIS}

\section{Género, consumo de alcohol y problemas relacionados con el alcohol en América Latina y el Caribe}

Durante la última década ha aumentado la preocupación por el consumo de alcohol como problema de salud pública. El consumo de alcohol es especialmente problemático en América Latina y el Caribe (ALC). Mientras que en todo el mundo la proporción de muertes atribuibles al alcohol es del 1,5\%, en los países de ALC esta cifra es del 4,5\%. Los esfuerzos para reducir los efectos negativos del alcohol sobre la sociedad y la salud pública necesitan tener en cuenta el contexto sociocultural en el que tiene lugar el consumo, y en particular los roles de género. Este tema ha sido tratado en un documento de trabajo publicado recientemente por el Banco Mundial, cuyo contenido se resume aquí. Dicho documento afirma que el consumo y el abuso de alcohol están relacionados con los roles de los hombres y las mujeres y sus expectativas en la sociedad. Los hombres tienen mayores probabilidades que la mujeres de beber mucho, y también menos probabilidades de abstenerse de consumir alcohol. Además, hay diferentes expectativas y significados del consumo de alcohol de unos y otras y de la forma como responden a él. Las políticas sobre el alcohol adoptadas por los gobiernos deberían basarse en la eficacia y en los costos de su puesta en práctica. Estas políticas pueden clasificarse en función de cuatro grandes objetivos: 1) prevenir el consumo y los comportamientos de alto riesgo relacionados con él; 2) reducir los daños a los consumidores individuales y a sus familias y comunidades; 3) regular la disponibilidad del alcohol y las condiciones de su consumo, y 4) proporcionarles tratamiento a personas con problemas relacionados con el alcohol. Las actuales medidas legislativas de los países de ALC tratan sobre todo de reducir la disponibilidad de bebidas alcohólicas, generalmente estableciendo una edad mínima para su consumo. Sin embargo, raramente se vela por el cumplimiento de estas leyes. El documento del Banco Mundial concluye con una serie de recomendaciones sobre las politicas y los programas de intervención, y también sobre las investigaciones que es necesario realizar para crear políticas de intervención más eficaces frente al alcohol. 